\title{
Modeling Short Run Relationship between Naira-USD Exchange Rate and Crude Oil Price in Nigeria
}

\author{
Saidat Fehintola Olaniran \\ Lecturer \\ Department of Statistics and Mathematical Science \\ College of Pure and Applied Sciences, Kwara State University \\ Malete, Kwara State
}

Nigeria

\begin{abstract}
The vector auto-regressive (VAR) model is one of the most successful, flexible, and easy to use models for the analysis of multivariate time series. It is a natural extension of the univariate auto-regressive model to a dynamic multivariate time series. The VAR model has proven to be especially useful for describing the dynamic behavior of economic and financial time series and for forecasting. It often provides superior forecasts to those from univariate time series models. The data used are monthly observations from January 2006 to October 2016 of Nigeria Crude Oil price and Naira to the dollar exchange rate. The VAR model was employed for modelling the data. The unit root test reveals that all the series are non-stationary at the level and stationary at first difference. The co-integration relations among the series indices were identified by applying Johansen's cointegration test. The result of Johansen's test indicates no existence of co-integration relation between the variables. The final result shows that a vector autoregressive (VAR) model of lag three with no co-integration equations best fits the data.
\end{abstract}

Key Words: Vector Autoregressive Model (VAR), Co integration, Unit Root Test, Naira-USD Exchange rate

\section{INTRODUCTION}

Most researchers have done considerable research on forecasting of the exchange rate for developed and developing countries using different approaches. The approach might vary in either fundamental or technical approach. Like the work of [1], used a technical approach to forecast Nigeria Naira - US dollar using seasonal ARIMA model from 2004 to 2011 . He reveals that the series (exchange rate) has a negative trend between 2004 and 2007 and was stable in 2008. His excellent work expatiates on that seasonal difference once produced a series SDNDER with slightly positive trend but still within discernible stationarity. Further works by [2], [3], [4], and [5] among others try to measure the forecast performance of ARMA and ARFIMA model on the application to US/UK pounds and Naira/US foreign exchange. They reveal that ARFIMA model was found to be better than ARMA model as indicates by the measurement criteria. Their persistent result reveals that ARFIMA model is more realistic and closely reflects the current economic reality in the two countries which was indicated by their forecasting evaluation tool. [6] used an intervention analysis to model the Nigeria exchange rate in the presence of financial and political instability from the period (1970 -2004). [7] researched the forecasting exchange rate between the Ghana cedis and the US dollar using time series analysis for the period January 1994 to December 2010. Their findings reveal that predicted rates were consistent with the depreciating trend of the observed series and $\operatorname{ARIMA}(1,1,1)$ was found to be the best model to such series and a forecast for two years were made from January 2011 to December 2012 and reveals that a depreciation of Ghana cedi's against the US dollar was found.

The theory of forecasting exchange rate has been in existence for many centuries where different models yield different forecasting results either in the sample or out of sample. The exchange rate which means the exchange one currency for another price for which the currency of a country (Nigeria) can be exchanged for another country's currency say (dollar). A correct exchange rate does have important factors for the economic growth for most developed countries whereas high volatility has been a major problem to economic series of African countries like Nigeria. There are some factors which affect or influences exchange 
rates like interest rate, inflation rate, trade balance, the general state of the economy, money supply and other similar macroeconomic giants' variables.

\section{MATERIAL AND METHODS}

Multivariate time series analysis was carried on Crude oil price and Naira to USD exchange rate over eleven years spanning through January 2006 to October 2016. The report also includes descriptive statistics, graphical plots, stationarity test, co-integration test and multivariate model estimation.

\subsection{Vector Autoregressive Model (VAR)}

The vector auto-regressive (VAR) model is one of the most successful, flexible, and easy to use models for the analysis of multivariate time series. It is a natural extension of the univariate auto-regressive model to a dynamic multivariate time series. The VAR model has proven to be especially useful for describing the dynamic behaviour of economic and financial time series and for forecasting. It often provides superior forecasts to those from univariate time series models. In addition to data description and forecasting, the VAR model is also used for structural inference and policy analysis. In structural analysis, certain assumptions about the causal structure of the data under investigation are imposed, and the resulting causal impacts of unexpected shocks or innovations to specified variables on the endogenous variables in the model are summarized. These causal impacts are usually summarized with impulse response functions and forecast error variance decompositions. The VAR model can be defined as

$$
Y_{t}=c+\Pi_{1} Y_{t-1}+\Pi_{2} Y_{t-2}+\ldots+\Pi_{p} Y_{t-p}+\varepsilon_{t} ; \quad t=1, \ldots, T
$$

where $Y_{t}=\left\{Y_{1 t}, Y_{2 t}, \ldots, Y_{n t}\right), p$ is the lag length, $\Pi_{i}$ is an $(n \times n)$ matrix of coefficients, $t$ is the period, $n$ denotes the numbers of endogenous variables.

\subsection{Stationary Vector Autoregressive Model (SVAR)}

The basic p lag vector autoregressive $\operatorname{VAR}(\mathrm{p})$ model in (1) can be generalized as:

$$
\begin{aligned}
& Y_{1 t=c_{1}}+\prod_{11}^{(1)} Y_{1, t-1}+\prod_{12}^{(1)} Y_{2, t-1}+\cdots+\prod_{1 n}^{(1)} Y_{n, t-1}+\prod_{11}^{(2)} Y_{1, t-2}+\prod_{12}^{(2)} Y_{2, t-2}+\cdots+\prod_{1 n}^{(2)} Y_{n, t-2}+\cdots+ \\
& \prod_{11}^{(p)} Y_{1, t-p}+\prod_{12}^{(p)} Y_{2, t-p}+\cdots+\prod_{1 n}^{(p)} Y_{n, t-p}+\varepsilon_{1 t} .
\end{aligned}
$$

The VAR (p) is stable if the root of

$$
\operatorname{det}\left(\mathbf{I}_{\mathrm{n}}-\prod_{1} \mathrm{Z}-\ldots-\prod_{\mathrm{p}} \mathrm{Z}^{\mathrm{p}}\right)=0
$$

(3) lies outside the complex unit circle (have a modulus greater than one), or, equivalently, if the eigenvalues of the companion matrix

$$
F=\left(\begin{array}{cccc}
\prod_{1} \prod_{2} & \cdots & \prod_{n} \\
I_{n} & 0 & \cdots & 0 \\
0 & \ddots & 0 & \vdots \\
0 & 0 & I_{n} & 0
\end{array}\right)
$$

have modulus less than one. Assuming that the process has been initialized in the infinite past, then a stable VAR (p) process is stationary with time-invariant means, variances, and autocovariance.

\section{EMPIRICAL RESULTS}

Table 1. gives the descriptive statistics and it shows that both the crude oil and Naira to USD are not normally distributed based on the p-value of the Jaque-Bera being less than 0.05. Hence logarithmic transformation is suggested before any further analysis. Fig1.(a) \& Fig1.(b) Shows the plot and it reveals a bilateral upward movement in the two series until 2015 before they started moving in the opposite direction. The time series under consideration should be checked for stationary before one can attempt to fit a suitable model. That is, variables have to be tested for the presence of unit root(s) thereby the order of integration of each series is determined. The stationarity of the series can be tested by using an Augmented Dickey-Fuller test. The results of ADF test with an intercept but no trend, and with intercept and trend at a level for each series is presented in Table 2., and the critical values used for the test is McKinnon critical values. Test results presented in Table 2. indicate that the null hypothesis that the series in level contain unit root could not be rejected for all the two series. That is, the respective p-values are greater than the conventional significance level $\alpha=0.05$. Since the null hypothesis cannot be rejected, to determine the order of integration of the non-stationary time series, the same test was applied using first differences. The order of integration is the number of unit roots 
International Journal of Advances in Scientific Research and Engineering (ijasre), Vol 5 (3), March-2019

that should be contained in the series to be stationary. The result in Table 3. indicates that the null hypothesis is rejected for the first differences of the two series given that the p-value less than 5\% level of significance with an intercept but no trend, and with intercept and trend. Therefore, the ADF test shows that all series are non-stationary in the levels, and stationary in the first difference.

Table 1. Descriptive statistics of Crude Oil price and Naira-USD

\begin{tabular}{|l|c|c|}
\hline Statistics & OIL & USD \\
\hline Descriptive Summary & & \\
\hline Mean & 84.43 & 173.27 \\
\hline Median & 79.76 & 159.06 \\
\hline Maximum & 138.74 & 462.03 \\
\hline Minimum & 30.66 & 118.70 \\
\hline Std. Dev. & 27.02 & 62.12 \\
\hline Skewness & -0.05 & 2.57 \\
\hline Kurtosis & 1.79 & 9.94 \\
\hline Observations (T) & 130 & 130 \\
\hline Normality Test & & \\
\hline Jarque-Bera & 7.94 & 404.25 \\
\hline Probability & 0.019 & 0.000 \\
\hline
\end{tabular}

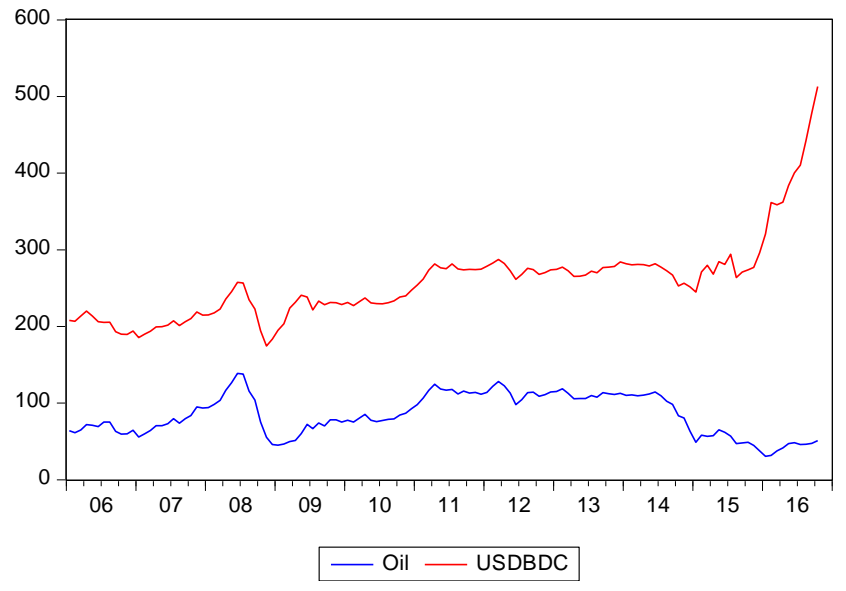

Fig 1. (a): Time plot of Original Series

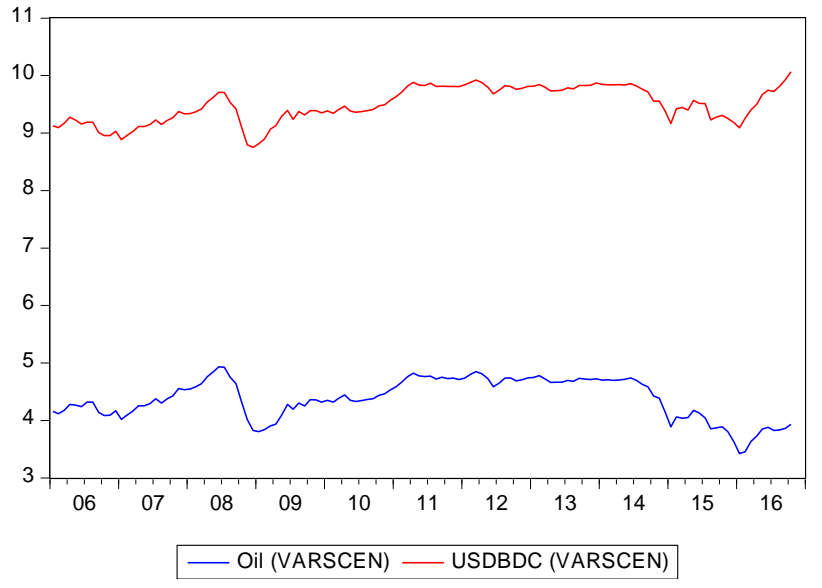

Fig 1. (b): Time plot of Transformed Series

Table 2. Unit Root Tests Result (Level)

\begin{tabular}{|l|c|c|c|c|}
\hline \multirow{3}{*}{ SERIES } & \multicolumn{2}{|c|}{ LEVEL WITH INTERCEPT } & \multicolumn{2}{c|}{ LEVEL WITH INTERCEPT AND TREND } \\
\cline { 2 - 5 } & Test statistic & Prob.* & Test statistic & Prob.* \\
& ADF & ADF & ADF & ADF \\
\cline { 2 - 5 } & -2.1585 & 0.2226 & -2.2589 & 0.4525 \\
\hline $\log ($ Oil $)$ & 2.4682 & 1.0000 & 0.5150 & 0.9993 \\
\hline $\log ($ USD) & &
\end{tabular}

Table 3. Unit Root Tests Result (After First Difference) 
International Journal of Advances in Scientific Research and Engineering (ijasre), Vol 5 (3), March-2019

\begin{tabular}{|l|c|c|c|c|}
\hline \multirow{3}{*}{ SERIES } & \multicolumn{2}{|c|}{ LEVEL WITH INTERCEPT } & \multicolumn{2}{c|}{ LEVEL WITH INTERCEPT AND TREND } \\
\cline { 2 - 5 } & Test statistic & Prob.* & Test statistic & Prob.* \\
\cline { 2 - 5 } & ADF & ADF & ADF & ADF \\
\hline $\log ($ Oil $)$ & -7.5705 & $<0.0001$ & -7.5989 & $<0.0001$ \\
\hline $\log ($ USD $)$ & -7.0684 & $<0.0001$ & -7.7540 & $<0.0001$ \\
\hline
\end{tabular}

Table4. Co-integration Analysis

\begin{tabular}{|c|c|c|c|c|}
\hline Hypothesized & & Trace & 0.05 & \\
\hline No. of CE(s) & Eigenvalue & Statistic & Critical Value & Prob.** \\
\hline None $*$ & 0.095800 & 15.20352 & 15.49471 & 0.0534 \\
\hline At most 1 & 0.026175 & 3.315417 & 3.841466 & 0.0686 \\
\hline
\end{tabular}

Trace test indicates no cointegrating eqn(s) at the 0.05 level

Unrestricted Cointegration Rank Test (Maximum Eigenvalue)

\begin{tabular}{|c|c|c|c|c|}
\hline Hypothesized & & Max-Eigen & 0.05 & \\
\hline No. of CE(s) & Eigenvalue & Statistic & Critical Value & Prob.** \\
\hline None & 0.095800 & 12.58810 & 14.26460 & 0.0905 \\
\hline At most 1 & 0.026175 & 3.315417 & 3.841466 & 0.0686 \\
\hline
\end{tabular}

Max-eigenvalue test indicates no cointegration at the 0.05 level

* denotes rejection of the hypothesis at the 0.05 level

Table 4. presents the co-integration analysis and it shows that either the trace test or maximum eigenvalue test indicates no cointegration at the 0.05 level, we, therefore, estimate the VAR.

\subsection{Estimating of the VAR Order}

Specifying the lag length has strong implications for subsequent modelling choices. For determining the appropriate lag length for the VAR model the Akaike Information Criteria (AIC, [8], [9]; [10] was used. Using AIC in Table 5., we can conclude that the fit is good at lag 3 and the optimum lag length is 3 . Having found that the variables are not co-integrated, we proceed to estimate the VAR model. The generalized form of the vector autoregressive (VAR) model can be specified as:

$$
\begin{gathered}
\operatorname{LUSD}_{t}=\varphi_{1}+\sum_{i=1}^{3} \alpha_{1} \operatorname{LUSD}_{t-i}+\sum_{i=1}^{3} \beta_{1} \text { LOil }_{t-i}+\varepsilon_{t} \\
\operatorname{LOil}_{t}=\varphi_{2}+\sum_{i=1}^{3} \alpha_{2} L_{U S D_{t-i}}+\sum_{i=1}^{3} \beta_{2} \text { LOil }_{t-i}+\varepsilon_{t}
\end{gathered}
$$

Table 5. Lag Length Criteria

\begin{tabular}{|c|c|c|}
\hline Lag & LogL & AIC \\
\hline 0 & -43.00050 & 0.737713 \\
\hline 1 & 369.2292 & -5.954577 \\
\hline 2 & 389.2863 & -6.217809 \\
\hline
\end{tabular}


International Journal of Advances in Scientific Research and Engineering (ijasre), Vol 5 (3), March-2019

\begin{tabular}{|c|c|c|}
\hline 3 & 394.5550 & $-6.238606^{*}$ \\
\hline 4 & 397.0250 & -6.213524 \\
\hline 5 & 401.3275 & -6.218483 \\
\hline 6 & 402.8444 & -6.177777 \\
\hline 7 & 409.6403 & -6.223611 \\
\hline 8 & 414.2508 & -6.233620 \\
\hline
\end{tabular}

In order to ascertain whether the model provides an appropriate representation, a test for misspecification should be perform. Portmanteau Q-statistic test for VAR model residual serial correlation is presented below. This test is used to test for the overall significance of the residual autocorrelations up to lag df is degrees of freedom for (approximate) chi-square distribution Since $\mathrm{p}$ value $(0.0631)>\alpha=0.05$ we cannot reject $\mathrm{H}_{0}$. Hence we conclude that there is no residual autocorrelation at lag 5 and it is white noise.

Table 6. VAR Model Estimate

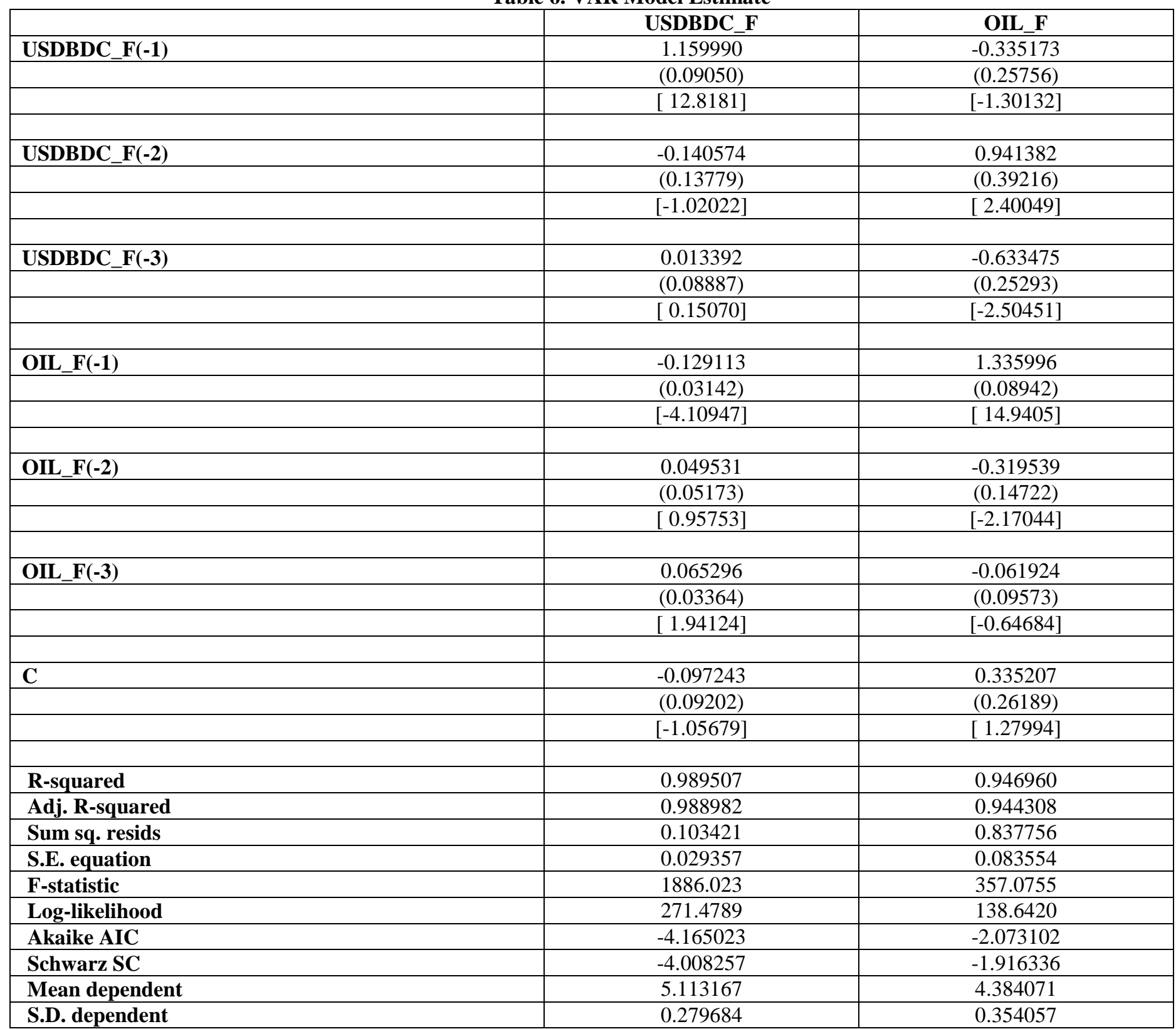

*** Estimates, Standard errors in ( ) \& t-statistics in [ ]

Table 6. Test for residual autocorrelation

\begin{tabular}{|c|c|c|c|c|c|c|}
\hline Lags & Q-Stat & Prob. & Adj Q-Stat & Prob. & df & \\
\hline
\end{tabular}


International Journal of Advances in Scientific Research and Engineering (ijasre), Vol 5 (3), March-2019

\begin{tabular}{|c|c|c|c|c|c|}
\hline 1 & 0.300004 & NA* & 0.302385 & NA* & NA* \\
\hline 2 & 0.411903 & NA* & 0.416074 & NA* $^{*}$ & NA* \\
\hline 3 & 9.534237 & NA* & 9.759110 & NA* $^{*}$ & NA* \\
\hline 4 & 10.92497 & 0.0274 & 11.19507 & 0.0245 & 4 \\
\hline 5 & 14.80458 & 0.0631 & 15.23368 & 0.0548 & 8 \\
\hline
\end{tabular}

*The test is valid only for lags larger than the VAR lag order.

\section{DISCUSSIONS OF RESULTS}

This study aims to fit a multivariate time series model for Crude oil price and Naira to the dollar exchange rate. The analysis was based on the monthly data from January 2006 to October 2016. In the study vector, autoregressive model (VAR) is used. Table 1. gave the descriptive statistics and it shows that both the crude oil and Naira to USD are not normally distributed based on the pvalue of the Jaque-Bera being less than 0.05. Hence log transformation was suggested before any further analysis. Figure 1.(a) and Figure 1.(b) revealed a bilateral upward movement in the two series until 2015 before they started moving in the opposite direction. The results of ADF test with an intercept but no trend, and with intercept and trend at the level for each series is presented in Table 2. the critical values used for the test is McKinnon (1991) critical values. Test results shown in Table 2. indicate that the null hypothesis that the series in level contain unit root could not be rejected for all the two series. That is, the respective p-values are greater than the conventional significance level $\alpha=0.05$. The result in Table 3 . indicated that the null hypothesis is rejected for the first differences of the two series given that the p-value less than $5 \%$ level of significance with an intercept but no trend, and with intercept and trend. Therefore, the ADF test shows that all series are non-stationary in the levels, and stationary in the first difference. The result of trace and maximum eigenvalue co-integration test presented in Table 4. revealed that no co-integration at the 0.05 level, then the VAR model can be assumed.

\section{CONCLUSION}

Over the period considered, the two series showed an increasing pattern, that is, there is the sign of non-stationarity in each of the series. To examine the VAR model, the unit root test (ADF test), identification of the number of lags, co-integration analysis and test for residual autocorrelation were conducted. Unit root test indicates that the indices are non-stationary at the level and are stationary at first difference at 5\% significant level. The Johansen cointegration test suggests that there is no co-integration vector. The appropriate number of lag determined was three and the portmanteau test indicates that the test was significant. Given the above findings, it is therefore recommended that if there is no co-integration in a multivariate time series data, it is better to fit a VAR model on the data.

\section{REFERENCES}

1. Etuk, E. H. (2012): “Forecasting Nigerian Naira-US Dollar Exchange Rates by a Seasonal Arima Model”, American Journal of Scientific Research; 59:71-78.

2. Olanrewaju I. Shittu and Olaoluwa S.Yaya (2008). "Measuring forecast performance of ARMA and ARFIMA model": An application to US dollar/ UK pounds foreign exchange”. European journal of scientific research 32 (2) 167 -176.

3. Newaz, M.K (2008); "Comparing the performance of time series models for forecasting exchange rate". BRAC university journal 2008 (2), 55-65.

4. Onasanya, O. K, Adeniji, O. E. (2013): "Forecasting of Exchange Rate between Naira and US dollar Using Time Domain Model"; International Journal of Development and Economic Sustainability; 1(1):45-55.

5. Osabuohien, I. O. and Edokpa, I. W. (2013): "Forecasting of Exchange Rate between Naira and US dollar Using Time Domain Model"; International Journal of Engineering invention; 2(4): 16-22.

6. Shittu, O.I (2008); "Modelling exchange rate in Nigeria in the presence of financial and Political Instability": an Intervention analysis approach”. Middle Eastern finance and economic journal, 2009 (5).

7. Appiah, S.T, Adetunde, I.A (2011); "Forecasting Exchange rate between the Ghana Cedi and the US dollar using time series analysis". Current research journal of economic theory, 3(2): 76 -83, 2011.

8. Akaike, H. (1973): “Information Theory and an Extension of the Maximum Likelihood Principle.”, In B. petov and F. csake, eds., a second international symposium on Information Theory. Budapest: Akademiai Kiado.

9. Hurvich, C. M, Tsai, C.L. (1989): "Regression and time series model selection in small samples", Biometrika 76: 297307.

10. Schwarz, G E. (1978): "Estimating the dimension of a model". Annals of Statistics 6 (2):461-464. 